University of South Florida

DIGITAL COMMONS

@ UNIVERSITY OF SOUTH FLORIDA
Digital Commons @ University of

South Florida

$12-1-2004$

\title{
Impacts of Transfer Fares on Transit Ridership and Revenue
}

CUTR

Follow this and additional works at: https://digitalcommons.usf.edu/cutr_nctr

\section{Scholar Commons Citation}

CUTR, "Impacts of Transfer Fares on Transit Ridership and Revenue" (2004). Research Reports. 228.

https://digitalcommons.usf.edu/cutr_nctr/228

This Technical Report is brought to you for free and open access by the National Center for Transit Research (NCTR) Archive (2000-2020) at Digital Commons @ University of South Florida. It has been accepted for inclusion in Research Reports by an authorized administrator of Digital Commons @ University of South Florida. For more information, please contact digitalcommons@usf.edu. 


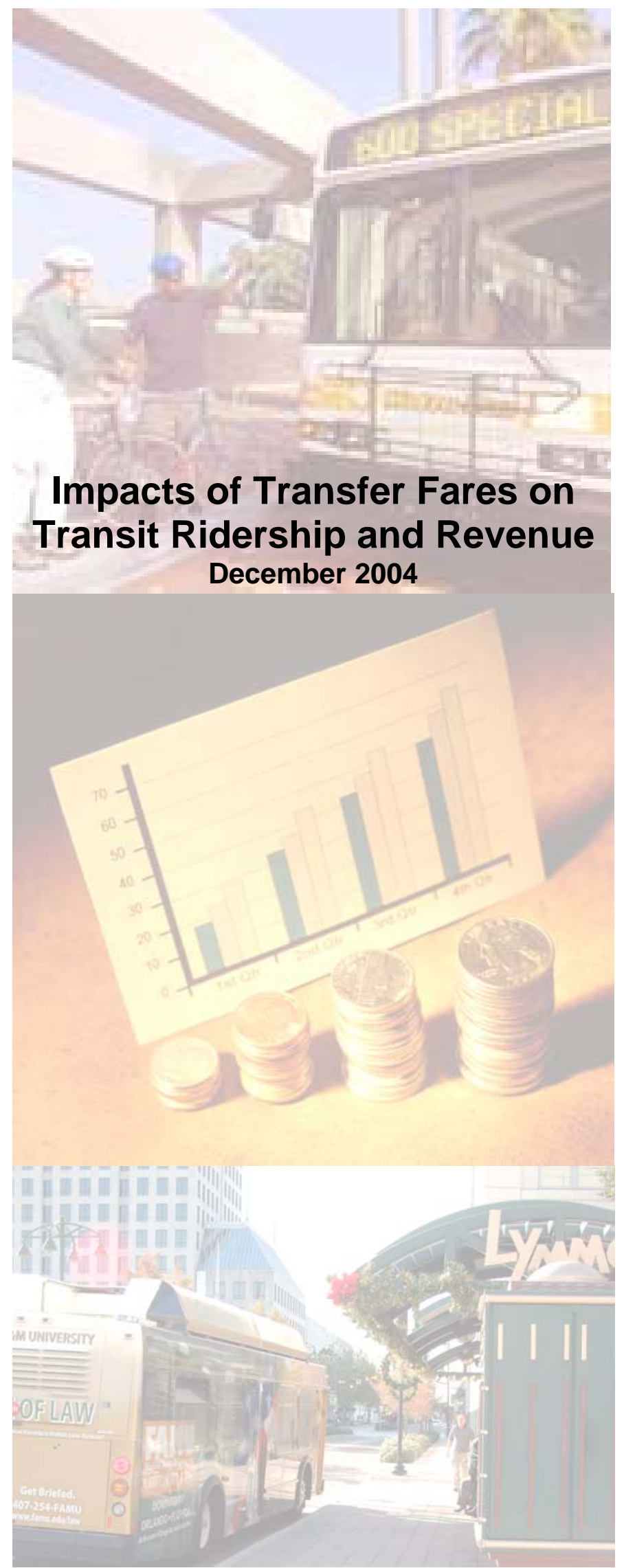

FDOT BC137- 44 


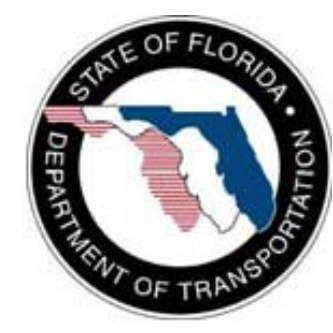

\section{State of Florida Department of Transportation}

Public Transit Office

605 Suwannee Street

Tallahassee, FL 32399-0450

(850) 414-4500

\section{Project Manager: Tara Bartee}

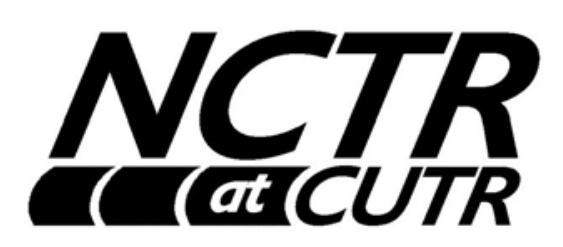

National Center for Transit Research

Center for Urban Transportation Research

University of South Florida

4202 E. Fowler Avenue, CUT 100

Tampa, FL 33620-5375

(813) $974-3120$

\section{Principal Investigator: Victoria Perk,} Senior Research Associate

The opinions expressed in this publication are those of the authors and not necessarily those of the U.S. Department of Transportation or the State of Florida Department of Transportation. 


\begin{tabular}{|c|c|c|c|}
\hline $\begin{array}{l}\text { 1. Report No. } \\
\text { NCTR - } 527-04 \\
\text { FDOT BC137-44 }\end{array}$ & 2. Government Accession No. & \multicolumn{2}{|c|}{ 3. Recipient's Catalog No. } \\
\hline \multirow{2}{*}{\multicolumn{2}{|c|}{$\begin{array}{l}\text { 4. Title and Subtitle } \\
\text { Impacts of Transfer Fares on Transit Ridership and Revenue }\end{array}$}} & \multicolumn{2}{|c|}{$\begin{array}{l}\text { 5. Report Date } \\
\text { December } 2004\end{array}$} \\
\hline & & \multicolumn{2}{|c|}{ 6. Performing Organization Code } \\
\hline \multicolumn{2}{|c|}{$\begin{array}{l}\text { 7. Author(s) } \\
\text { Perk, Victoria; Volinski, Joel; and Kamp, Nilgün }\end{array}$} & \multicolumn{2}{|c|}{ 8. Performing Organization Report No. } \\
\hline \multirow{2}{*}{\multicolumn{2}{|c|}{$\begin{array}{l}\text { 9. Performing Organization Name and Address } \\
\text { National Center For Transit Research (NCTR) } \\
\text { University of South Florida CUT } 100 \\
4202 \text { East Fowler Avenue, Tampa, FL } 33620\end{array}$}} & \multicolumn{2}{|l|}{ 10. Work Unit No. } \\
\hline & & \multicolumn{2}{|c|}{$\begin{array}{l}\text { 11. Contract or Grant No. } \\
\text { DTRS98-G-0032 }\end{array}$} \\
\hline \multirow{2}{*}{\multicolumn{2}{|c|}{$\begin{array}{l}\text { 12. Sponsoring Agency Name and Address } \\
\text { Office of Research and Special Programs (RSPA) } \\
\text { U.S. Department of Transportation, Washington, D.C. } 2 \\
\text { Florida Department of Transportation } \\
605 \text { Suwannee Street, MS 26, Tallahassee, FL } 32399\end{array}$}} & \multicolumn{2}{|c|}{ 13. Type of Report and Period Covered } \\
\hline & & \multicolumn{2}{|c|}{ 14. Sponsoring Agency Code } \\
\hline \multicolumn{4}{|c|}{$\begin{array}{l}\text { 15. Supplementary Notes } \\
\text { Supported by a Grant from the USDOT Research and Special Programs Administration, and the Florida } \\
\text { Department of Transportation }\end{array}$} \\
\hline \multicolumn{4}{|c|}{$\begin{array}{l}\text { 16. Abstract } \\
\text { Transfers are used by the transit industry to allow passengers to move between routes in the } \\
\text { system. This gives the riders flexibility to reach locations that are not provided by a direct } \\
\text { connection, which due to cost constraints and system design are not always possible. However, } \\
\text { using transfers as part of the fare structure creates additional burden on the operator that collects } \\
\text { the fares, the agency that provides the media and the bookkeeping, the rider that pays for the } \\
\text { transfer, and the additional time added to the trip due to the transaction. Transfer policy aside from } \\
\text { the fare can be complex. How long is the transfer usable? What are the policies for transfers } \\
\text { between modes? What is the transfer media? How are transfers tracked in the system? An } \\
\text { easier approach might be to eliminate transfer fares altogether; however, the short-term and long- } \\
\text { term impacts on revenue and ridership are not clear. Proponents of free transfers and those who } \\
\text { advocate eliminating or charging for transfers usually rely on various assumptions. The need for } \\
\text { research investigating the impacts of transfer policy and fares on revenue and ridership is } \\
\text { imminent. }\end{array}$} \\
\hline $\begin{array}{l}\text { 17. Key Words } \\
\text { public transit, fare policy, fare } \\
\text { elasticities, transfers, transit } \\
\text { ridership }\end{array}$ & $\begin{array}{l}\text { 18. Distribution Statement } \\
\text { Available to the public t } \\
\text { Service (NTIS), 5285 P } \\
\text { 487-4650, http://www.n } \\
\text { http://www.nctr.usf.edu }\end{array}$ & $\begin{array}{l}\text { Rational } \\
\text { Road, Spri } \\
\text { nd through }\end{array}$ & $\begin{array}{l}\text { Information } \\
22161,(703) \\
\text { web site at }\end{array}$ \\
\hline $\begin{array}{l}\text { 19. Security Classif. (of this report) } \\
\text { Unclassified }\end{array}$ & $\begin{array}{l}\text { 20. Security Classif. (of this page) } \\
\text { Unclassified }\end{array}$ & $\begin{array}{l}\text { 21. No. of pages } \\
55\end{array}$ & 22. Price \\
\hline
\end{tabular}

Form DOT F 1700 


\section{Impacts of Transfer Fares on Transit Ridership \& Revenue (BC 137 RPWO \#44)}

\section{Table of Contents}

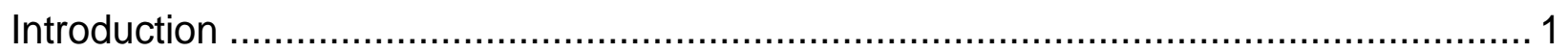

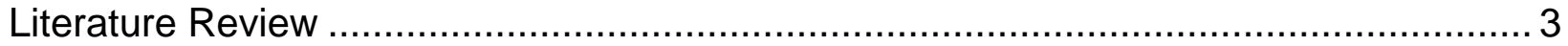

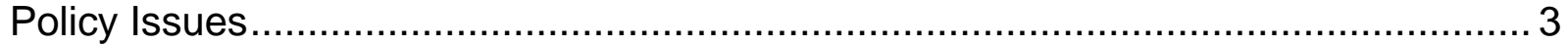

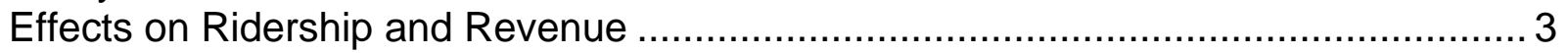

Pricing and Fare Elasticities............................................................................ 4

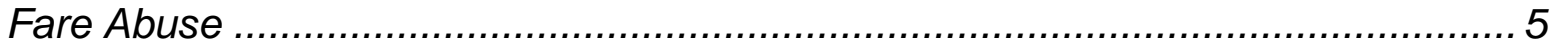

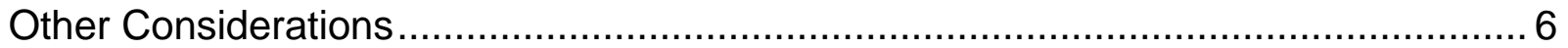

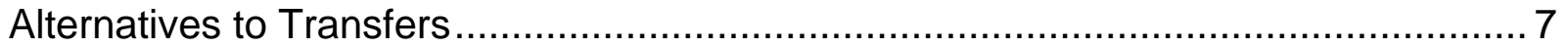

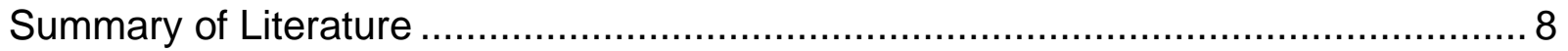

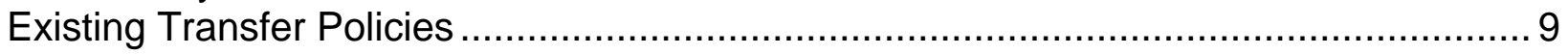

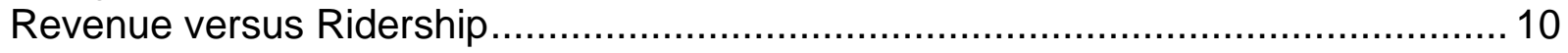

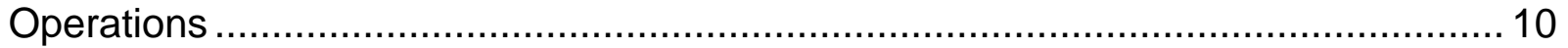

Methods of Determining Transfer Policies ...................................................... 11

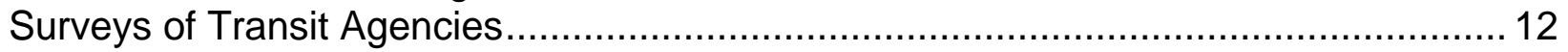

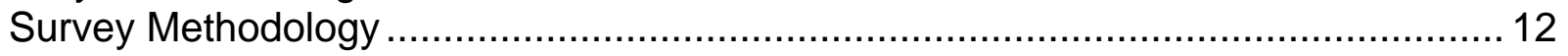

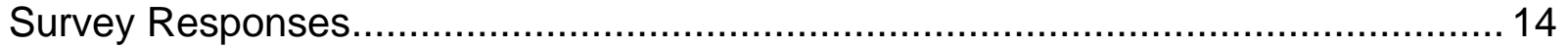

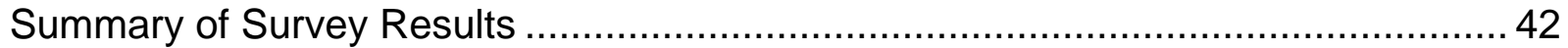

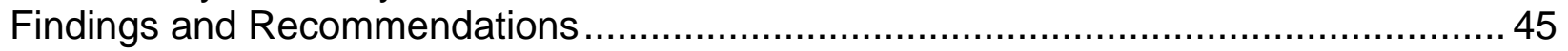

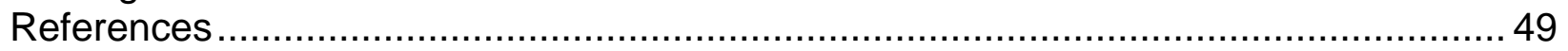




\section{Introduction}

As part of its National Center for Transit Research (NCTR) Program, the Center for Urban Transportation Research (CUTR) conducted research for the Florida Department of Transportation (FDOT) to investigate how transit transfer fares and policies affect ridership and revenue, and to examine the reasoning for the implementation of these fares as it pertains to policy, budgetary, and operational issues.

Transfers are used to allow passengers to move between routes or modes in one or more transit systems. The transfers give riders the flexibility to reach locations that are not provided by a direct connection within the route network. Because of cost constraints and system design, providing a direct connection between all locations is not possible and transfers will always be needed with fixed-route services. However, using transfers as part of the fare structure creates additional burden on the vehicle operator who collects the fares, the agency that provides the media and the bookkeeping, the rider that pays for the transfer, and the additional time added to the trip due to the transaction. At times, transfer policy can be quite complex with various time and/or mode limitations on transfers. A simpler approach might be to eliminate transfer fares altogether; however, short- and long-term effects of such an initiative on revenue and ridership are not always clear.

Currently used methodologies and techniques and the state-of-the-art practices related to impacts of fare structure changes are presented in this report. In addition, this report also develops recommendations to assist transit agencies in the evaluation of transfer fare and policy changes as a tool for decision making.

This project included five distinct tasks that were designed to achieve the objectives listed above. First, a literature review was conducted pertaining to transfer policy. CUTR reviewed and summarized previous studies related to transfers. A significant amount of research has been dedicated to exploring fare policies and the impacts of fare structure changes on transit revenue and ridership. Based on results from the literature review, as well as peer-to-peer discussions, a series of currently used methodologies related to transfer policy were identified in the second task of this project. These include, but are not limited to, procedural frameworks as well as

qualitative evaluation using different fare elasticity measures. Special attention will be given to the reasoning behind the selection of these methodologies; in particular, relating to policy considerations, budgetary, and operational issues. Based on the findings from the first two tasks, a questionnaire survey instrument was developed to determine the specific components of and issues faced by transit agencies on the implementation of transfer policy/fare changes. Feedback 
from the surveyed transit agencies related to motivation, methodologies, and political issues. The purpose of the survey, administered as part of the fourth task of this project, was to collect information related to the nature of any relationship between revenue and ridership due to changes in the transfer policy and fare structure as well as the agency motivation to implement such changes. In addition, key personnel were interviewed regarding customer characteristics, agency objectives, and methodologies used during this process. Finally, the survey was used to gather pertinent lessons learned from the selected transit agencies.

The final task of this research compiled the results of all previous tasks to develop a synthesis of the best practices in the evaluation of transfer policy/fare changes. Successful endeavors are highlighted, as well as challenges facing these types of fare structure and policy changes. Overall, the findings of this study seek to isolate specific characteristics or conditions that contribute to success, as well as those that present challenges to overall effectiveness and success. In addition, recommendations are offered related to the appropriateness of changing transfer fares/policy and the relevance of future technologies.

The results of this study are largely based on the qualitative results of the surveys. Definitive results derived through quantitative analysis were not able to be achieved because the changes in fare policies observed through the case studies in the survey were almost always occurring at the same time as several other events, both internal and external to the agencies. The value of the results is in the experiences and lessons learned from the agencies that participated in the study. One notable quantitative result, however, is that, when paired with the implementation of new fare collection technology, an agency's revenue was found to increase approximately five percent when transfers were eliminated. 


\section{Literature Review}

As discussed previously in the Introduction section, as part of the analysis, CUTR conducted an in-depth literature search on transfer policies. Although there was a vast amount of prior research on fare policies and the impacts of fare structure changes on transit ridership, literature dedicated to other aspects of transfers was somewhat limited. The following paragraphs summarize these studies.

Although most systems need to transfer passengers, transit agencies do not appear to be in consensus on how to price such transfers. According to the American Public Transportation Association's (APTA) 2002 Transit Fare Summary, approximately 55 percent of the responding agencies offer transfers with a surcharge either within the same mode or between different modes. The remaining agencies do not require transfer charges either because the service is free, an agency operates a one-line system, or transfers are not given and a second full fare must be paid when a passenger boards another vehicle.

\section{Policy Issues}

Part of this differentiation may be explained by the various goals and objectives of transit agencies. As part of the TCRP Synthesis 19, "Passenger Transfer System Review” (1996), transit agency personnel who were interviewed ranked the importance of various objectives in determining their transfer policies. The top five items listed included promoting ridership, reducing rider difficulty, coordinating schedules, preventing fare abuse, and collecting the correct fare amount. In other words, while promoting ridership may require a reduced charge for transfers, preventing fare abuse could be more easily achieved by not offering transfers altogether (i.e., by requiring a second fare).

\section{Effects on Ridership and Revenue}

Clearly, the nature of the transfer pricing and policy affects revenue and ridership. As explained in TCRP Report 10, "Fare Policies, Structures, and Technologies” (1996), free or low-price transfers produce higher ridership and less revenue than do full-fare per boarding structures. The revenue is affected both by the pricing itself and the potential for fare abuse. 


\section{Pricing and Fare Elasticities}

Since the 1960s, various price sensitivity/elasticity research findings have been published. Although there does not appear to be any literature that specifically focuses on the elasticity of transfers; whether increasing or reducing transfer charges affects ridership much as fare increases or decreases do. This section provides a summary of fare elasticity research findings.

An early study, John F. Curtin's “Effects of Fares on Transit Riding” (1968), established the Simpson-Curtin formula, which predicts the percentage decrease in ridership as a function of the percentage increase in fares. Over the years, this formula became the rule of thumb with an estimate of a 0.3 percent increase (decrease) in transit ridership for every one percent decrease (increase) in fares over their previous level. Studies conducted later established that, although the Simpson-Curtin formula is generally correct for overall system analysis and in highlighting the fact that transit ridership demand is price inelastic, there is still a wide variation in transit fare elasticity values.

According to TCRP Report 27, "Building Transit Ridership" (1997), short-term direct transit fare elasticities tend to vary from -0.1 to -0.7 , with most estimates clustering between -0.2 and -0.5 . Kemp, in his article titled "Some Evidence of Transit Demand Elasticities" (1973), found that the elasticities are numerically small when the purpose of travel is a relatively strong one (such as the work trip) or when alternative means of transportation are unavailable, highly priced, or provide markedly inferior travel time. In other words, transit fare elasticities tend to be numerically low for work-related trips, peak-period services, and service in dense central city areas. Demand is most sensitive to price at off-peak times, for short trips, in relatively affluent markets, and places without much traffic congestion. In addition, transit demand is often observed to be more sensitive to changes in the price of private vehicle travel than to transit fare changes. This is partially due to the larger base of private vehicles trips that can potentially be diverted to transit than the base of existing trips.

The article by Mayworm et. al., titled "Patronage Impacts of Changes in Transit Fares and Services" (1980), states that aggregate elasticity values, such as the Simpson-Curtin formula, are adequate only to describe the elasticity for all trip purposes, all periods of days, and all types of passengers. However, aggregate values do not address the variations within a given transit system operation. The article provides a list of factors affecting the elasticity level such as city population, transit mode, type of fare change, trip length, route type, time periods, trip purpose, income, and age. Some of the other literature that confirms these types of variations include Dygert, Holec and Hill, 1977; Grey Advertising, 1977; Webster and Bly, 1980; and Fairhurst and 
Morris, 1975. In their 1999 report, Dargay and Hanly also observed that demand is more price sensitive at higher fare levels.

Linsalata and Pham, in their 1991 APTA study titled "Fare Elasticity and Its Application to Forecasting Transit Demand," applied a Box-Jenkins transfer function (ARIMA) model to systemwide time series data for each system in a sample of 52 responding systems. Their results are largely in line with the findings of previous literature. However, the study highlights how large the variations among systems can be. The system-wide, all-period fare elasticities vary from -0.12 to -0.85 . Although Linsalata and Pham acknowledged a city size effect, they were unable to identify other reasons for this variation.

The TCRP Project B-12, titled “Traveler Response to Transportation System Changes” (2000), confirms the variations in elasticities. Among other areas of variation, it points out bus feeder services to rapid transit being significantly more sensitive to fare increases than other bus ridership. This finding may shed some light as to the price elasticity of at least one type of transfer (bus to rail).

\section{Fare Abuse}

As mentioned previously, an agency's fare revenue is also affected by the potential for fare abuse. TCRP Report 10 and TCRP Synthesis 19 cite various forms of the abuse, including:

- giving or selling transfers to other riders, who would otherwise pay a full fare;

- round-tripping, where a passenger boards a bus inbound and requests a transfer, then uses the transfer to board an outbound bus and return to the point of origin without paying a second fare;

- stopover, in which case the passenger gets off the bus enroute and later reboards a bus on the same route going in the same direction;

- $\quad$ passengers trying to use expired transfers by punching additional holes, marking up an old transfer to look like it was issued on the current day, etc.;

- passengers "passing back" a transfer, passing it out the window of the stopped bus to another boarding passenger;

- passengers stealing transfer pads from the bus, in some cases with the driver's connivance; and

- transfer counterfeiting rings, encouraged by the fact that transfers are typically printed on inexpensive, low security newsprint paper. They tend to be easy to duplicate using a photocopy machine or simple printing equipment. 
In addition, agencies mentioned frequent driver-passenger disputes involving transfers. In fact, according to agencies interviewed in preparation of the TCRP Synthesis 26, "Bus Transit Fare Collection Practices" (1997), the most common cause of fare disputes was arguments over transfers. TCRP Synthesis 19 reports the following initiatives to reduce or eliminate these disputes and transfer fare abuse:

- implement new transfer policy or change the existing policy (e.g., reduce the time for which transfers are valid, etc.);

- provide operator training in human relations or other courses;

- distribute bulletins to operators;

- improve the design of the transfer to make it easier for the operator to see and determine validity;

- operator observations with undercover spotters and supervisors or increased observation at major transfer points, in some cases coupled with strong discipline;

- coordinate with the police, including investigation and recording street sales with videotape;

- improve passenger education and information; and

- use automated equipment that can issue and read magnetically encoded transfers. For example, as explained by David Lee in his paper published in Transportation Research Record 1669, when Connecticut Transit started using Ticket Reading and Issuing Machine (TRIM) technology, the agency benefited from information on "cut time” being clearly printed on each transfer and the units validating the transfers of boarding customers. This eliminated the need for drivers to scrutinize transfers presented and resulting disputes.

\section{Other Considerations}

As explained in TCRP Report 10, in addition to revenue and ridership, the transfer policy also affects operations, especially the role and responsibilities of the bus operator. In addition, the transfer policy must address the use of transfers, including the number of transfers that will be permitted for full fare, the amount of time allowed for a transfer, and whether the transfer can be used for round-tripping or "stopovers." Other administrative concerns include the requirements for printing, daily distribution, and accounting for transfers. 


\section{Alternatives to Transfers}

The literature review suggests that there are several alternatives to transfers. Three of these include multi-hour passes (passes good for several hours, but less than a day), day passes, and prepayments such as multi-ride or weekly/monthly passes. These options eliminate the need for a transfer because unlimited transfer privileges are included. There are several advantages and disadvantages of these alternatives.

Advantages include the following:

- Elimination of many abuses of the traditional transfer system such as back-riding and stopovers.

- Alternative media such as passes can be smaller, and/or used more than once, thus saving paper.

- Potential for confrontation between passengers and drivers is reduced.

- The transit agency is selling a certain number of hours of transportation that may be used in any way the passenger wishes. Policy makers see this as a logical approach that does not penalize any group.

- Passes allow passengers to take additional trips without paying an additional fare; thus, they often take additional trips, such as during midday periods (lunch, etc.). This increases the value of the transit agency to the passenger and the community, and increases ridership during the off-peak when there is normally excess capacity.

- Day passes are easier for drivers to handle, as they do not require punching or tearing for the time of day or route. No interpretation beyond date of issue is required.

According to Volinski ("Lessons Learned in Transit Efficiencies, Revenue Generation and Cost Reductions"), the all-day pass has proven to be highly successful not only in terms of ridership and revenue, but in terms of driver-passenger relations, improved running time, and reduced fare abuse.

However, these passes are not without certain disadvantages, including:

- Such passes can still be abused (i.e., illegal sharing) because they are valid for unlimited rides during a certain length of time. According to TCRP Report 10, Muni in San Francisco experienced a tremendous revenue loss when it attempted to replace transfers with day passes. Rather than issuing dated passes on the bus, Muni used its 
visitor pass, which requires the user to scratch off the current day. Many riders failed to do so and used a single pass for several days. Muni ultimately reinstated transfers.

- These types of passes may not appeal to a rider who makes a single linked trip per day. Typically this is not a large market but should be considered.

- Administrative requirements associated with accounting for transfers are exacerbated with long-term passes due to the higher value of the passes compared to transfers. Similarly, because drivers are carrying high-value fare instruments, the temptation to steal such documents is high. There is also greater exposure to counterfeiting.

- The number of dollar bills handled in fareboxes may increase and there may be a problem with high value currency such as \$5 and \$10 notes (fareboxes cannot differentiate currency values).

- Revenues are lost from passengers who use day passes at a higher rate than pricing would indicate.

Another alternative to transfers is to offer no transfer privilege and require payment of a second full fare whenever boarding another vehicle. However, this approach likely decreases ridership.

\section{Summary of Literature}

A review of available literature on transfer fares suggests that transit agencies are not in consensus whether to implement special transfer fares, provide free transfers, or not provide transfers at all. While agencies who are primarily concerned with ridership tend to provide free or low-fare transfers, agencies that are concerned about fare revenue are inclined to not offer lower transfer fares and require a second full fare. Agencies' overall fare revenues are affected both by the level of transfer fares and fare abuse, which is a serious concern in the area of transfers. Some of the alternatives to transfers include multi-hour or day passes or prepayments. Although these resolve some of the problems agencies face due to transfers, they do generate their own challenges. In addition to trade-off between ridership and revenues, transfers also affect operations, especially in terms of bus operators' responsibilities.

The next section of this report summarizes transfer policies that are commonly used by transit agencies. 


\section{Existing Transfer Policies}

Based on the literature review and peer-to-peer discussions, the most common transfer types appear to be the following:

- free transfers;

- low-priced transfers (i.e., a fraction of the full fare cash);

- no transfers (i.e., full fare for each boarding); and

- “upgrade” fares for transferring between different operators’ services or modes.

In addition, some agencies also adopt transfer policies directed to certain groups. Examples include:

- free transfers for elderly and disabled passengers;

- elderly and disabled passengers discount equivalent to half the base rate, rounded to the closest five cents; and

- no discount on transfers for elderly or disabled passengers.

In addition to pricing, transfer policies vary in terms of the use of transfers. Examples of areas where these variations occur include:

- the number of transfers allowed per full fare (i.e., one, two, or unlimited transfers within a given time limit);

- the amount of time allowed for a transfer (i.e., one, two, or more hours after the initial full-fare boarding);

- whether transfers can be used for round-tripping or stopovers;

- intermodal transfers; and

- interagency transfers.

In deciding which policy to follow, some of the key considerations that must be weighed include agency goals related to the trade-off between revenue and ridership, and other operational issues, as discussed below. 


\section{Revenue versus Ridership}

The nature of the transfer pricing and policy affects revenue and ridership. While free or lowpriced transfers increase ridership and generate less revenue, a "no transfer" policy, (i.e., full fare for each boarding), generates more revenue with lower ridership. In the case of free or lowpriced transfers, lower revenues result not only from the fact that transfers are priced low, but also from fare abuse as discussed in the previous section.

Similarly, in the case of use of transfers, agencies that are more interested in increasing ridership tend to be more flexible while agencies that concentrate on generating revenues tend to have more strict rules on the use.

Agencies interviewed in the preparation of the TCRP Synthesis 19 cited the following five objectives as their primary transfer system objectives, which relate to ridership or revenue levels:

- Promoting ridership;

- Reducing rider difficulty;

- Coordinating schedules;

- Preventing abuse; and

- Collecting correct fare amounts.

\section{Operations}

In addition to revenue and ridership, the transfer policy also affects operations, particularly the role and responsibilities of the bus operator. As also explained in TCRP Report 10, depending on the structure of transfer use, the operator will have to check a user's transfer media for acceptable time (i.e., within the allowable usage period), route, direction, or combinations thereof. The more restrictive the policy (e.g., no round-tripping or stopovers on a single route), the greater the potential for operator-rider conflicts.

As mentioned previously, other administrative concerns include the requirements for printing, daily distribution, and accounting for transfers, as well as potential theft of transfer media from buses. 


\section{Methods of Determining Transfer Policies}

TCRP Synthesis 19 reports that the primary techniques used to develop transfer policies include:

- Driver input;

- Public hearings;

- Market surveys; and

- Passenger focus groups.

Some of the less frequently mentioned techniques mentioned include analysis of historical practice, employee input, research of other transit agencies, and informal passenger input.

This section provided a summary of common transfer policies and factors that are important in defining a transfer policy. The next section of this report summarizes the survey effort undertaken as part of this project. 


\section{Surveys of Transit Agencies}

A major effort for this project was a survey of transit agencies across the U.S. regarding experiences with transfer policy. Based on the findings from the previous tasks of this study, a survey was developed and administered to determine the specific components of and issues faced by transit agencies on the implementation of transfer policy/fare changes. Specific topics that were addressed include operational, budgetary, policy, and efficiency impacts of these changes. Related issues were also addressed as they were introduced by survey participants. Finally, feedback from transit agencies related to motivation, methodologies, and political issues were considered. The results of the survey, along with the results of other tasks, were used in the final task of this project to develop a synthesis of best practices in the evaluation of transfer policy/fare changes.

This task consisted of the development and conduct of surveys with transit agencies that have implemented recent changes in transfer policy/fares. The purpose was to collect information related to the nature of any relationship between revenue and ridership due to changes in the transfer policy and fare structure as well as the agency motivation to implement such changes. In addition, key personnel were interviewed regarding customer characteristics, agency objectives, and methodologies used during this process. Ultimately, the survey was used to gather pertinent lessons learned from the selected transit agencies.

\section{Survey Methodology}

During Spring and Summer 2004, a total of 29 transit agencies were surveyed for this effort. Surveys were conducted via telephone using a prepared list of questions/topics that were developed using the results of the first two tasks of this project: the literature review and identification of current methodologies. The survey questions included the following topics:

- Current transfer policy, including price, length of usability of transfers, transfers between modes, media type, and tracking;

- When the current policy was implemented and, if applicable, what the previous policy was;

- The impacts of any change in transfer policy, including impacts relating to operations, budget, policy, efficiency, and ridership;

- Motivation and method for making any change in transfer policy; 
- Challenges encountered by the agency in implementing a new transfer policy (including political challenges, etc.);

- Characteristics of customers who transfer; and

- Lessons learned from agencies that have implemented new transfer policies.

The transit agencies that participated in this survey are listed below. Following this list is a brief summary of each agency's response.

- Broward County Transit (Ft. Lauderdale, FL)

- Bus Valley Ride (Boise, ID)

- Cambria County Transit Authority (Johnstown, PA)

- Chattanooga Area Regional Transportation Authority (TN)

- Chittenden County Transportation Authority (Burlington, VT)

- Community Transit (Snohomish County, WA)

- Delaware Transit Corporation (DE)

- Durham Area Transit Authority (NC)

- Glendale, California (CA)

- Hampton Roads Transit (Hampton, VA)

- Hillsborough Area Regional Transit Authority (Tampa, FL)

- Memphis Area Transit Authority (TN)

- Metro Area Transit (Omaha, NE)

- Metro Transit (Minneapolis, MN)

- OMNITRANS (San Bernardino, CA)
- Orange County Transportation Authority (CA)

- Palm Tran (West Palm Beach, FL)

- Pee Dee Regional Transportation Authority (Florence, SC)

- Regional Transit System (Gainesville, FL)

- Rhode Island Public Transit Authority (RI)

- Rochester-Genessee Regional Transportation Authority (MI)

- San Joaquin Regional Transit District (Stockton, CA)

- Sun Metro (El Paso, TX)

- Sun Tran (Tucson, AZ)

- Transfort (Fort Collins, CO)

- Utah Transit Authority (UT)

- Visalia City Coach (CA)

- Williamsport Bureau of Transportation (PA)

- Windham Region Transit District (Willimantic, CT) 


\section{Survey Responses}

The following pages provide a brief summary of the survey responses received for this project.

Agency: $\quad$ Broward County Transit - BCT (Ft. Lauderdale, FL)

Current Fare and Transfer Policy: $\quad$ Base cash fare is $\$ 1.00$.

All-Day pass is $\$ 2.50$.

No transfers are issued.

Effects of Changes in Policy: Prior to October 2002, BCT’s base fare was $\$ 1.00$ and transfers were issued for $\$ 0.15$. Transfers were valid for two hours and were restricted to certain routes. With the purchase of new GFI Odyssey fareboxes, BCT implemented its All-Day pass and eliminated transfers. It is difficult to isolate the impact of the change in fare policy because BCT was also adding service and providing the opportunity to use 31-Day passes as well as the All-Day passes. Ridership increased steadily by approximately five percent. The change in fare policy appears to have been revenue neutral.

Motivation for Changes: BCT instituted these changes to offer more flexibility to passengers, to eliminate the disputes between passengers and bus operators over the validity of transfers, to eliminate the cost of purchasing books of transfers, and to increase ridership.

Problems: There were very few negative comments or complaints from passengers who might have been inconvenienced by discontinuing the issuance of transfers.

Other Changes Planned: BCT is part of a region that is reviewing the possibility of establishing a regional pass and regional fare collection system. However, there are no specific plans to modify he fares for intracounty travel at the time this report was written; although, the farebox recovery ratio has decreased from 28 percent to 25 percent due to increased costs. 
Agency: Bus Valley Ride (Boise, ID)

Current Fare and Transfer Policy: Base fare is $\$ 1.00$ with free transfers.

There are no time restrictions on the use of the transfer, but the use is restricted to certain connecting routes.

No round-tripping is allowed.

Newspaper quality transfers are torn by the bus operators and handed to passengers.

Effects of Changes in Policy: The base fare was raised to $\$ 1.00$ from $\$ 0.75$ in 2003; transfers have been free for many years. There was no noticeable change in ridership due to the base fare increase.

Problems: Passengers tend to complain that they cannot use the transfer on certain routes if they stop to shop and try to get on a bus back in the same direction, or on the same bus headed in the same direction.

Other Changes Planned: The agency is planning to purchase new fareboxes that can issue and validate transfers and All Day passes.

Motivation for Changes: They recognize that the All Day pass is more convenient for many passengers, but they also see it as an opportunity to generate additional revenue through advertising on the passes that are issued from the farebox. The agency is looking forward to the opportunity to sell passes with prepaid amounts programmed into the cards as a way of increasing sales to employers that will buy such passes on behalf of their employees. 
Agency: Cambria County Transit Authority (Camtran, Johnstown, $\underline{\mathrm{PA})}$

Current Fare and Transfer Policy: Base fare is $\$ 1.35$ and transfers are available for $\$ 0.20$. Transfers are valid for two hours, can be used only once, and are restricted to use on connecting routes.

Effects of Changes in Policy: Camtran's basic fare policy has remained the same for a number of years, although in 2002 the base fare was raised from $\$ 1.30$ and transfers were raised from $\$ 0.10$. In fact, the agency decided to ask its Board for a graduated fare increase over a five-year period from $\$ 1.25$ to $\$ 1.50$ by having the fare increased by $\$ 0.05$ each year. In addition, the agency purchased GFI Odyssey fareboxes that automated the issuance and validation of transfers. Ridership has decreased since the fare increase, but the agency believes the decrease is more attributable to a weak economy and a harsh winter that limited the number of trips people would take. Many riders are older and retired, and take discretionary trips that decrease with harsh weather.

Motivation for Changes: The theory behind the graduated fare increase is that the agency believed it was better to go to their board one time, rather than needing to go back repeatedly to ask for additional increases.

Problems: Camtran reported no significant problems with the new fares or the new farebox equipment. There were occasional farebox jams, but it was not difficult for the maintenance personnel to change and repair the units. There were very few complaints regarding the change in fares, and teaching passengers about the new way transfers were issued from the farebox was also easily accomplished by the bus operators.

Other Changes Planned: No significant changes are planned. 
Agency: Chattanooga Area Regional Transportation Authority (CARTA, TN)

Current Fare and Transfer Policy: Base fare is $\$ 1.00$ for cross-city routes and transfers to other cross-city routes are $\$ 0.20$.

Transfers are valid for the next connecting bus, regardless of the time it takes for that bus to arrive.

The type of transfer used is of the traditional newspaperquality and is punched by the bus operator.

CARTA redesigned its services in 1998 to institute neighborhood routes with a different fare structure. The base fare for a ride on a neighborhood route is $\$ 0.50$. To transfer to a cross-city route from a neighborhood route, passengers must pay another $\$ 0.50$. On a return trip, passengers pay the $\$ 1.00$ base fare for the cross-city route, $\$ 0.20$ for a transfer to another cross-city route, if necessary, and the transfer to a neighborhood route is free.

Effects of Changes in Policy: When the fare system noted above was instituted in 1998, there were too many other changes being implemented at the same time to be able to isolate the effects of the fare change. CARTA was creating neighborhood routes for the first time, adding new service routes, and improving headways on major routes.

Problems: There are too many manual processes involved with the current paper transfers, including ordering and storing of transfers, issuance to bus operators and then to passengers, and the need to clean up remnants from punched transfers. CARTA acknowledges that there are equity issues that can be raised by those who might complain that people making short trips on cross-city routes should not have to pay more than people making neighborhood trips; however, this has not been a major issue.

Other Changes Planned: CARTA will use the existing fareboxes for three more years. Everything is "on the table" in terms of future changes. The agency is strongly considering All Day passes and Three Day passes, given the tourism in the area. CARTA is also exploring the possibility of Smart Cards that could be used in conjunction with the local Chamber of Commerce for the many events that take place in the downtown area. This will also give them the opportunity to consider eliminating transfers altogether.

Motivation for Changes: Cumbersome manual processes with paper transfers are the motivation for CARTA to explore other options. 
Agency: Chittenden County Transportation Authority (Burlington, VT)

Current Fare and Transfer Policy: $\quad$ Base fare is \$1.00, and transfers are free. Transfers are valid for one hour, and can only be used on the next connecting bus.

Transfers are issued and validated by electronic fareboxes.

Effects of Changes in Policy: The current fare policy has been in effect for at least 15 years, so there is no record of changes in available. New fareboxes were installed in 2001 that allowed the validation of transfers. The agency believes the new fareboxes helped reduce fraudulent use of transfers and thereby helped increase revenue slightly.

Problems: n/a

Other Changes Planned: No changes in fare policy are planned at this time.

Motivation for Changes: The new fareboxes helped eliminate arguments between passengers and bus operators, and also helped speed the boarding process to enable buses to stay on schedule. 
Agency: Community Transit (Snohomish County, WA)

Current Fare and Transfer Policy: Base fare is \$1.00, and transfers are free.

There is a two-hour window in which to use a transfer from the time of boarding a bus, and this transfer can be used on any route, in any direction.

The transfer is newspaper quality and is torn off and punched by the bus operators.

Effects of Changes in Policy: The base fare was changed from $\$ 0.80$ to $\$ 1.00$ in 1998, but the policy of issuing free transfers was not changed.

Problems: The agency did not indicate that there were problems with passengers paying for travel within Snohomish County.

Other Changes Planned: Snohomish County is part of the greater Seattle metropolitan area with five transit agencies all engaged in developing a true regional fare policy. It appears that the region will move to new technology using Smart Cards. The agency believes it will still allow a two-hour window for free transfers from an initial bus ride. In addition, the agency is considering programming the new fareboxes to stop charging a passenger's Smart Card once charges of $\$ 2.50$ are accumulated in one day.

Motivation for Changes: As discussed, the agency is part of a region with five transit systems that have been deliberating about how to establish a regional fare system with shared revenues among systems. That issue goes beyond the scope of this particular study. 


\section{Agency: Delaware Transit Corporation}

Current Fare and Transfer Policy: The fare policy is comprehensive, but somewhat complex because it is based on zones throughout the state. For areas in the state with 10,000 miles of service or more, the cash base fare is $\$ 1.15$. In counties with less service than 10,000 miles of service, the cash base fare is $\$ 1.00$.

There are seven fare zones that have different levels of service, including premium service, offered. A fare for multizone services that include premium service costs $\$ 1.50$ per zone. All Day passes are offered at 2.1 times the base fare per zone; e.g., an All Day pass used within areas where base fares are $\$ 1.00$ would cost $\$ 2.10$ for service within that zone. The pass costs $\$ 2.40$ in zones where the base cash fare is $\$ 1.15$. A premium All Day pass for use of any transit service in the state is available for $\$ 9.45$ ( $\$ 4.50 \times 2.1)$. The agency capped the cost of that premium pass based on the maximum rate for three zones. The agency also sells magnetic strip stored value cards. They do not issue transfers.

Effects of Changes in Policy:

The agency inherited several other county agencies that had different fare structures and dissimilar transfer policies among them. First, the agency coordinated the schedules of the various routes within the state to make transfers easier for passengers. They then purchased new fare equipment that could read stored value cards. They held extensive meetings with their bus operators, passengers, and community groups to receive input on how to restructure the fare policy. One result was that Weekly and Monthly passes were eliminated due to the fact that many who purchased such passes only used them four or five days a week and did not want to pay for days that they did not use service.

In the end, the number of different fares offered (including discounts for elderly and disabled) was reduced from 33 to 18. ACME stores are selling the stored value cards and they are not charging the transit agency any administrative fee for this service. Almost 70 percent of all passengers use the stored value cards, resulting in considerable foot traffic into the ACME stores.

These changes were instituted in May 2001. The events of September 11, 2001 and the consequent loss of jobs due to 
the downturn in the economy affected transit ridership in a way that makes it difficult to isolate the effect that the change in fare policy had on ridership and revenue. For example, the vacancy rate in downtown Wilmington increased from 2 percent to 21 percent during this time. Pre-paid sales of transit stored value cards remained the same, though cash sales dropped and ridership decreased. Agency representatives believe the drop in ridership was less than proportional to the drop in the economy, and that the changes were revenue neutral.

Motivation for Changes: There were 33 different fare options for passengers. This was unwieldy for passengers and operators alike, and there were limitations on how many combinations of fares the fareboxes could accommodate.

Problems: None reported. The new fare structure was very well received by the public after being carefully crafted with considerable public input. Very few people were making one-way trips that required a transfer, hence there were few complaints about the elimination of transfers.

Other Changes Planned: No other changes are planned at this time 
Agency: Durham Area Transit Authority (Durham, NC)

Current Fare and Transfer Policy: Current base fare is $\$ 1.00$, and transfers are issued free of charge.

Transfers are valid for 45 minutes from time of issuance and restricted to certain connecting routes.

Traditional newspaper quality transfers are used and punched/torn by bus operators.

Most transfers are used at the downtown terminal where there is a pulse system that operates.

Effects of Changes in Policy: The cash base fare was changed from $\$ 0.75$ to $\$ 1.00$ in 2003. Transfers remained free. The change in ridership was negligible. The agency believes that because most passengers are "captive," the change in fare had little effect on ridership.

Problems: The agency is not satisfied with the accuracy of ridership counts through its fareboxes and is anxious for more accurate data through better equipment. This agency experiences the same issues with transfers that every agency does in terms of disputes between passengers and bus operators over the validity of transfers.

Other Changes Planned: The agency purchased new fareboxes in 2004 which will allow for better accounting of passenger data. They are considering a number of alternatives including the institution of All Day passes. They are also considering eliminating transfers and reducing the base fare back to $\$ 0.75$. 


\section{Agency: Glendale, California}

Current Fare and Transfer Policy: The cash base fare is $\$ 0.25$.

Given the low base fare, no transfers are issued, and passengers pay $\$ 0.25$ each time they board.

Effects of Changes in Policy: The agency has never had a fare system that has included route-to-route transfers within its own system. For $\$ 0.50$, passengers can get a transfer to a Los Angeles Metropolitan Transit Authority bus. The system carries thousands of passengers with mostly short trips, so a low fare is appropriate.

Problems: Glendale's policy of no transfers is designed to avoid the problems that most transit agencies experience of fraud, disputes, and administrative headaches of accounting for transfers. The city contracts for service and keeps its costs under $\$ 50$ per hour for the service it provides.

Other Changes Planned: The Los Angeles region is in the midst of designing a new regional fare collection system that will be based on Smart Card technology. When that occurs, Glendale will play an appropriate role. 
Agency: Hampton Roads Transit (Hampton, VA)

Current Fare and Transfer Policy: The base fare is $\$ 1.50$.

Transfers are free and can be used for two hours from the time of issuance, though their use is restricted to certain connecting routes.

Passengers can transfer twice with the transfer. Transfers are issued and validated by electronic fareboxes.

Motivation for Changes: Hampton Roads Transit is a recently-created transit agency formed by joining the former Pentran and Tidewater Regional Transit agencies into one organization. The two former agencies had different base fares and transfer policies. Pentran had a base fare of $\$ 1.50$ with free transfers while Tidewater featured $\$ 1.00$ base fares and transfers for $\$ 0.10$.

Hampton Roads Transit hired a consulting firm to develop a uniform fare system for the new agency that was equitable for all passengers and easier to understand and administer. It was also the intent to generate additional revenue for the transit agency to compensate for increased fuel costs and labor contract costs while retaining the maximum number of passengers possible.

Effects of Changes in Policy: The agency adopted a new fare structure that called for a new base fare of $\$ 1.50$ applied throughout the combined district. To help offset this increase in base fare to half of the district, transfers would be made available free of charge, and discounted ten-ride and 31-day passes would be offered. New fare collection equipment purchased by the agency allowed such instruments to be read and validated. The projections are for fares to increase by 4.8 percent, while ridership is expected to decrease by 0.7 percent.

Problems: Representatives of the agency indicated that, despite the substantial increase in the base fare for half of the service district, there were very few complaints from the riding public. The new farebox equipment made the heavily discounted ten-ride and 31-day passes easy to administer, and these instruments eased the burden of the increased base fare.

Other Changes Planned: These changes to the fare system were only recently instituted, and there is no plan to change anything in the near future. 
Agency: Hillsborough Area Regional Transit (HARTline, Tampa, $\underline{\mathrm{FL}}$

Current Fare and Transfer Policy: The cash base fare is $\$ 1.30$.

HARTline does not issue transfers.

An All-Day pass is available for $\$ 3.00$.

Motivation for Changes: Prior to 1997, Hartline issued newspaper quality transfers with restrictions on their use. When the All-Day pass was instituted, the agency was also in the process of reducing service due to budgetary constraints.

Effects of Changes in Policy: At the time the All-Day pass was implemented, ridership declined, and they found it difficult to assess the impact that the fare change had on ridership or revenue. However, passenger acceptance was very high. Today, almost 50 percent of all passengers use the All-Day pass. Transfer activity is very high, and the All-Day pass helps provide passengers with small savings and helps the transit agency maintain its schedules more effectively. The new fareboxes that the agency purchased allowed the All-Day passes to be issued and validated electronically. The fareboxes were also able to read and validate 20 -ride tickets, 31-day tickets, and three-day visitor passes.

Ridership has increased since the time that service was cut back, and ridership has gone up nicely since then, but it is still difficult to determine the effect of the fare policy change because the hours of revenue service have fluctuated significantly over the years.

Problems: The previous system of issuing transfers manually was "a nightmare" that too often resulted in disputes between passengers and the bus operators. There are virtually no disputes now that the farebox determines the validity of a pass. The passengers were pleased with the All-Day pass as an option for paying fares. There were a few mechanical glitches with the new fareboxes, but HARTline trained both its bus operators and field supervisors to correct the most basic problems.

Other Changes Planned: The agency is anticipating an increase in the base fare of $\$ 0.05$, but it is not planning any change to its fundamental policy of using the All-Day pass in lieu of transfers. 
Agency: $\quad$ Memphis Area Transit Authority (Memphis, TN)

Current Fare and Transfer Policy: The base fare is \$1.25 and transfers are \$0.10. The transfer can only be used on the next bus, and drivers are well versed in what routes the transfers may be used on. However, passengers can "transfer on a transfer" if required.

Traditional newspaper quality transfers are used and punched by bus operators.

Effects of Changes in Policy: There have been no changes in the basic cost of transfers, or the policy of transfer use, in many years. The base fare was changed from $\$ 1.10$ to $\$ 1.25$ in 2000 .

Problems: The agency reports no particular problems with its transfer policy.

Other Changes Planned: There are no changes currently being discussed. 
Agency: Metro Area Transit (Omaha, NE)

Current Fare and Transfer Policy: The cash base fare is $\$ 1.25$.

Transfers cost $\$ 0.05$ and are valid for one hour from the time the passenger leaves the bus. The transfer may be used more than once, but is restricted directionally. These transfers are the traditional newspaper quality and are torn and punched by the bus operator.

Motivation for Changes: Metro Area Transit is seeking ways to stem the decline in ridership that has been experienced for years. Ridership has fallen from 20 million passengers per year in 1978 to less than 4 million passengers per year in 2003. Hence, the agency is planning a major renovation by changing the service into a hub-and-spoke system. Longer routes will travel from one of eight hubs to the others, while local routes will stay within smaller areas and feed the hubs.

Effects of Changes in Policy: The agency is deciding on the fare policy to apply to this new service delivery method. One proposal is to charge $\$ 0.50$ for trips on neighborhood spoke routes, with transfers priced at $\$ 0.05$, thus allowing the passenger to transfer to a hub connector route. The same transfer could be used to ride within the neighborhood zone as many times as the passenger would like for up to four hours. On a return trip from a hub connecting route, the base fare would be $\$ 1.25$, with a transfer to a neighborhood spoke route costing $\$ 0.05$. The other alternative is to maintain the current fare structure with deeply discounted monthly passes. The new service delivery method is scheduled for implementation in August 2004.

Problems: The new service will be implemented in August 2004. However, the first proposed change to the fare structure described below has raised concerns about a serious decrease in revenue, and the possibility of equity issues being raised for different fares being paid for different trips. It appears more likely that the current fare structure will remain in place, with the hopes that the revised service technique will attract more riders. Unfortunately, a grant request that would have provided funds to purchase new fareboxes was not approved. This grant would have allowed the agency to sell and validate 31-day passes and other flexible time-based fare media.

Other Changes Planned: The changes that are planned are described above. Many transit professionals from around the country will be watching the results of this route restructuring plan. 
Agency: $\quad$ Metro Transit (Minneapolis, MN)

Current Fare and Transfer Policy: The current cash base fare is \$1.25.

Transfers are issued free of charge and are valid for two and a half hours.

Passengers may transfer on a transfer, but they are restricted directionally.

Effects of Changes in Policy: No recent changes have occurred or are planned.

Problems: No significant problems were reported by the agency.

\section{Agency: OMNITRANS (San Bernardino, CA)}

Current Fare and Transfer Policy: The base cash fare is $\$ 0.85$.

Transfers are available for $\$ 0.10$.

The transfers are restricted in terms of the routes they can be used on and are valid within one and a half hours of issuance. Also, an All Day pass is available for \$2.25.

Motivation for Changes: OMNITRANS conducted extensive passenger surveys in 1996 and found that 40 percent of all passengers had to transfer to complete their trip, and 65 percent of all passengers made more than four trips per day. Hence, in 1997, OMNITRANS instituted the All-Day pass.

Effects of Changes in Policy: The All-Day pass was implemented even though the agency did not have fareboxes that could issue and validate such passes. OMNITRANS operated with this manual mode of issuing All-Day passes before installing fareboxes that issued and validated the cards. The agency indicated there was a 26 percent increase in ridership in the first year the All-Day passes were used, but notes that service was being added and other route changes were being made during the same time. Hence, it is difficult to gauge the actual effect of the All-Day pass, but the agency is confident it contributed positively to ridership.

Problems: The agency takes pride in having well-trained bus operators who are capable of enforcing fare policies on board buses. The relatively simple method of including serial numbers on the All-Day passes and reconciling the farebox entry data with the records of All-Day passes that were issued to bus operators at the beginning of their run assignments worked well. There was some minimal fraud among passengers who would print their own versions of 
the All-Day pass, but the agency estimated the rate of fraud was no higher than two percent. Highly disciplined and trained bus operators were a major factor in keeping the effects of such fraudulent attempts to a minimum.

Other Changes Planned: No changes are planned for the near future.

Agency: Orange County Transportation Authority (Orange, CA)

Current Fare and Transfer Policy: The base fare is \$1.00, and transfers are not issued. An All-Day pass is available for $\$ 2.50$.

The agency installed new fareboxes that allow the sale of 30-day passes with rolling dates rather than monthly passes that are based on calendar months.

Effects of Changes in Policy: Before the All-Day pass, the base fare was \$0.75, and transfers cost $\$ 0.10$. Transfers were valid for one hour and were restricted to connecting routes. The agency instituted a \$2.00 All-Day pass before they had equipment that could issue or validate them. Each day's pass had the new date, and each month they were issued in a different color to help reduce fraud. The agency believes the effect on ridership and revenue was fairly neutral. A major advantage is the robust database they now have on ridership patterns by time of day, by route segment, etc. The fareboxes are also tied to the radio system, allowing for tracking boardings by stop. In June 2002, the fare for All-Day passes was increased to $\$ 2.50$, resulting in a modest drop in ridership and a modest increase in revenue; however, ridership resumed previous levels shortly thereafter. The agency believes the economy has much more effect on ridership than small changes in fare policy.

Problems: Despite the manually-issued All-Day passes, the agency did not experience significant problems. A total of 75,000 passes per day were disbursed to bus operators who sold 35,000 per day. The 30-day passes discussed above have proven popular to the point where All-Day pass sales have been reduced to 25,000 per day.

Other Changes Planned: California transit agencies are required to meet at least 20 percent farebox return to be eligible for certain state grants. With its farebox return at about 23 percent, the agency sees a need to increase fares in the near future; although its fundamental fare policy will not change. 
Agency: Palm Tran (West Palm Beach, FL)

Current Fare and Transfer Policy: The base fare is $\$ 1.25$. No transfers are issued. An All-Day pass is available for $\$ 3.00$.

Effects of Changes in Policy: The agency estimated that approximately 35 percent of its passengers transferred to complete their trips. In 1999, Palm Tran discontinued issuing transfers when they started offering All-Day passes. Prior to the institution of the AllDay pass, the base fare was $\$ 1.00$ and transfers were available for $\$ 0.20$. The transfers issued were the traditional newspaper quality media that were torn and punched by bus operators. There was no time restriction on the use of the transfer as long as it was used on the day of issuance. The transfer could be used on any route, but could not be used to roundtrip on the same route. A transfer was good for only one use.

The agency has experienced an almost 40 percent increase in ridership since the change in fare policy, but they do not attribute a good deal of this to the change in fare policy. They believe the reallocation of service hours from weak routes to their busiest routes was the primary driver of the ridership increase; however, they acknowledge that the All- Day pass played some role in the increase.

Problems: Palm Tran received some complaints when transfers were eliminated, but not as many as they thought they would receive. Although the All-Day pass offered new flexibility for many passengers, the increase in the base fare had a neutralizing effect on the increase in ridership due to the fare policy change. In addition, the price of the All-Day pass was higher than in most other areas of the country and the ratio of base fare to All-Day pass fare was higher than in most other areas of the country.

Motivation for Changes: The driving force behind establishing a higher fare for the All- Day pass was the enormous potential demand for ADA trips in the service area. More than one-third of the agency's budget is for paratransit, and the agency wanted to encourage people to use the fixed-route service as much as possible by making the paratransit fare, which is twoand-a-half times the base cash fare, less attractive.

Other Changes Planned: Palm Tran indicated that ridership is continuing to grow even though the agency is not adding service hours, and they have no plans for additional changes in the fare structure. 
Agency: $\quad$ Pee Dee Regional Transportation Authority (Florence, SC)

Current Fare and Transfer Policy: The base cash fare is $\$ 1.00$.

Transfers are available for $\$ 0.50$.

A transfer may be used once, but is not time restricted.

The transfers are the traditional newspaper stock that are torn and punched by the bus operator.

Effects of Changes in Policy: This fare policy has been in effect for many years. The routes in this service area are very long; therefore, they do not think that the transfer fee of $\$ 0.50$ is too high.

Problems: Agency representatives claim there are no significant problems with the current fare policy.

Other Changes Planned: There are no discussions to modify the current fare policy.

Agency: Regional Transit System (Gainesville, FL)

Current Fare and Transfer Policy: The cash base fare is $\$ 1.00$, and transfers are not issued. All-Day passes are available for $\$ 2.00$.

RTS operates in a community with a large university (University of Florida), where students are able to ride for free when boarding by showing student identification cards.

Effects of Changes in Policy: Prior to 1997, RTS charged a $\$ 1.00$ base fare and $\$ 0.25$ for transfers. In 1997, RTS discontinued the use of transfers and established the All-Day pass. It must be noted that the system also changed from a network that focused on the downtown to one that focused on the university. Routes were changed from once every 45 minutes to once every 30 minutes or 60 minutes, and interlocal agreements were reached with the university to encourage more transit use by students. The All-Day pass put regular passengers on more of an equal footing with university students who could ride on an unlimited basis. It also helped minimize the costs to people who used to have one-seat rides before the transit system was realigned to focus more on the university with higher frequencies, but more transfers.

Ridership exploded from approximately 2 million passengers per year in 1997 to over 8 million passengers per year in 2004. Given the multiple changes in route structure and system emphasis, it is difficult to determine the impact of the change in the fare structure on ridership and revenue. 
Problems: In the years that transfers were used, there were considerable problems in accounting for them. Boxes of transfers would disappear, and many were found in waste paper baskets on the bus not validated or punched. The All-Day pass presented challenges of its own in terms of accountability, but they were numbered sequentially and were given different colors for each month. While this created a considerable amount of work for dispatchers, the agency felt the change was well worth it.

Other Changes Planned: No changes are planned at this time.

Agency: $\quad$ Rhode Island Public Transit Authority (RIPTA)

Current Fare and Transfer Policy: The cash base fare is \$1.25.

Transfers are available for $\$ 0.10$.

The transfers are of traditional newspaper stock and are valid for two hours, but cannot be used on the same route.

Effects of Changes in Policy: In July 2002, the RIPTA Board of Directors reduced the cost of transfers from $\$ 0.25$ to $\$ 0.10$. The change in ridership and revenue was minimal because 70 percent of all passengers use flash passes and less than 5 percent of passengers request transfers.

Problems: Despite the relatively small number of passengers who use transfers, the agency is anxious to discontinue the use of transfers as part of their fare policy. Bus operators have been known to accept anything from grocery store receipts to fast-food restaurant receipts and accept them as valid fare, rather than get into disputes with passengers who are obviously abusing the service. Administering transfer policies is also confusing for bus operators and passengers.

Other Changes Planned: RIPTA hopes to have new fareboxes and a smart card system in place by the end of 2005 . When these are installed and implemented, the agency will discontinue the issuance of transfers. They intend to maintain the same base fare, offer All-Day passes for $\$ 3.00$, 11-ride passes for $\$ 12.25$ and a 31-day pass for $\$ 45.00$. They believe that the smart card system will provide far superior ridership analysis, eliminate fraud, help increase revenue, and be more flexible and convenient for customers. 
Agency: Rochester-Genesee Regional Transportation Authority

Current Fare and Transfer Policy: The cash base fare is $\$ 1.25$.

Transfers are available for $\$ 0.15$.

The transfers are issued and validated by GFI fareboxes with TRIM units.

Transfers are valid for two hours, and are restricted to use on certain routes.

All-Day passes are available for $\$ 4.00$, a 20-ride pass is available for $\$ 20.00$, and a 31-day pass is available for $\$ 56.00$.

Effects of Changes in Policy: In 1992, the base fare was increased from $\$ 1.00$ to $\$ 1.25$ and the transfer charge was increased from $\$ 0.10$ to $\$ 0.15$. This resulted in a decrease in ridership of 8.3 percent. In the late 1990s, the agency installed new fareboxes that could issue and validate transfers and read stored value fare media. Although the fares remained the same and service remained relatively the same, cash revenues increased by approximately 10 percent. Over 55 percent of all passengers transfer, and there had apparently been a considerable amount of fraud with the use of transfers that the new fareboxes eliminated.

Problems: The new flexible fare instruments helped ridership increase, but the increase in cash revenues of almost $\$ 4,000$ per day was attributed to the elimination of fare abuse with transfers.

Other Changes Planned: The agency is very happy with the current policies. They are looking at the possibility of purchasing new fareboxes and changing to smart card technology to allow for better financial accounting and more extensive fare options. 
Agency: San Joaquin Regional Transit District (Stockton, CA)

Current Fare and Transfer Policy: The base cash fare is \$1.10 and transfers are \$0.05. The transfers are restricted in terms of what directions the holder can travel in, though they are not time restricted. The transfers are issued and validated by GFI TRIM unit fareboxes.

All-Day passes are also sold for $\$ 3.00$. This policy provides the maximum options for passengers who may only make one-way trips each day and might require a transfer to complete their one-way trip.

Effects of Changes in Policy: San Joaquin's fare policies and equipment have been in place for almost ten years. Records of changes in revenue and ridership based on changes to fares in 1996 were not readily available.

Problems: The structure of the routes require many passengers to continue proceeding in one direction in order to complete their trip or connect to a bus that was going in the direction of their final destination (A-frame trip patterns). Because the transfer policy was based on direction, this caused many people to have to pay two fares to complete a single trip.

Other Changes Planned: The agency instituted a fare change in 2004 that will increase the base fare from $\$ 1.10$ to $\$ 1.25$. The agency recommended doing away with transfers, but the public stated they still wanted them, due to the fact that some riders only take one-way trips in the course of a day. The policy board is likely to increase the transfer charge from $\$ 0.05$ to as much as $\$ 0.15$. The staff believes that the fare changes being proposed are neutral in terms of ridership, and should result in a modest increase in revenue. In addition, the agency will change its transfer policy from being directionally restricted to being time restricted. Passengers will be able to transfer to any route, but the transfer will be good for only one hour. 
Agency: Sun Metro (El Paso, TX)

Current Fare and Transfer Policy: The base cash fare is $\$ 1.00$. Transfers are issued for $\$ 0.10$.

Transfers are of the traditional newspaper quality that are torn off and punched by the bus operator. They are valid for one hour and can only be used on certain connecting routes.

Effects of Changes in Policy: The current fares have not changed in over five years. The agency realizes it needs to do a thorough review and analysis of ridership patterns before making any major changes to its fare policies.

Problems: The agency's best estimate is that over 50 percent of its passengers transfer to complete their trips. There are an unacceptable number of disputes and altercations between passengers and bus operators over the issue of transfers.

Other Changes Planned: Sun Metro is two years away from buying new fareboxes that can validate and issue transfers or other fare media. They have considered eliminating transfers altogether and charging $\$ 0.75$ for all trips. However, the agency knows it needs to evaluate its passengers' travel characteristics. If over 50 percent of passengers transfer, it might not be wise to charge a new base fare every time someone boards. Sun Metro is also planning on building a number of neighborhood terminals and circulators that will require even more transfers. 


\section{Agency: Sun Tran (Tucson, AZ)}

Current Fare and Transfer Policy: The base cash fare is $\$ 1.00$.

Transfers are issued for free and are valid for two additional trips within two hours of issuance. There are restrictions as to the routes transfers can be used on, and no round trips are permitted.

All-Day passes are available for $\$ 2.00$.

Effects of Changes in Policy:

Sun Tran added the TRIM units that print and validate tickets and transfers to their fareboxes in 1999. There was a noticeable switch among passengers who started to purchase the All-Day pass for $\$ 2.00$ rather than paying base fares and/or asking for transfers. Ridership remained the same, while revenue went up slightly.

In 2000, the agency increased its base fare from $\$ 0.85$ to $\$ 1.00$ while maintaining free transfers and the same price for All-Day passes of \$2.00. However, Sun Tran also eliminated its Youth Pass, requiring young passengers to either pay full fare or prove they were in households making below the federal poverty level, making them eligible for the "economy fare." With that change, ridership decreased 4 percent, although revenue increased 16 percent. As with so many other transit agencies, there were too many changes being made to the system to allow a clear analysis of what impact the changes in transfer policy had on ridership and revenue.

Motivation for Changes: Sun Tran went forward with the new fareboxes and AllDay passes partially because they are an agency committed to using the best technology available.

Problems: Transfers were a significant problem to deal with prior to the installation of the TRIM units. However, there does not seem to be a significant problem currently.

Other Changes Planned: The agency might consider raising the fare for the All-Day pass, which is very reasonably priced, though there is no specific thought as to what the appropriate amount might be. They will also reconsider whether they should still continue to issue transfers since the All-Day pass is available. 
Agency: Transfort (Fort Collins, CO)

Current Fare and Transfer Policy: The base fare is $\$ 1.25$ with free transfers.

Transfers are valid for one hour, and there are no restrictions on how they can be used, but they can only be used once. The transfers are of the traditional newspaper quality, punched by bus operators.

Effects of Changes in Policy: The base fare was raised from \$1.00 to \$1.25 in January 2004. Ridership dropped, but there were other changes being made to the system that make it difficult to determine what exact effect the change in base fare had on ridership or revenue. The policy of free transfers was not changed and has been in effect for many years.

Problems: The agency has minimal problems when it comes to transfers because over 60 percent of the passengers are either college or high school students who are allowed to ride the bus free of charge upon boarding with their student identification cards. They have had a few problems with passengers who appear to be older than high school age who show high school IDs, but not enough to require major changes to their fare policy.

Other Changes Planned: The agency has no plans to change policies or equipment in the near future. The agency discussed purchasing new fareboxes that would allow the issuance of different fare media and transfers, but a tight budget prevented them from going forward with new fare equipment. As noted earlier, the majority of those who ride are students who use identification cards. This minimizes the need for new fareboxes or changes in transfer policies. 
Agency: Utah Transit Authority (UTA)

Current Fare and Transfer Policy: The cash base fare is $\$ 1.35$ and transfers are free. Transfers may be used in any direction, on any bus. There is also no charge for transferring from a bus to the light rail system.

A free fare zone exists in the downtown area.

Effects of Changes in Policy: Transfers have always been free at UTA, but fares increased from $\$ 0.85$ in 2001 to $\$ 1.35$ in 2004 . Monthly passes increased from $\$ 32.00$ to $\$ 45.00$ during the same time frame. Ridership has varied during that time due to many factors including the opening of a new light rail line, the demand in ridership due to the Winter Olympics, and the 2003 reopening of the I- 15 corridor which had been closed to traffic for four years. Hence, it is again difficult to identify the impact that the change in fare policies has had on ridership and revenue due to these other major factors and the slowed economy during the same time.

UTA uses older farebox technology, but tried offering AllDay passes that were issued manually by bus operators. The revenue for the agency dropped, but not alarmingly, and the agency believes that the drop was due to fare evasion.

Problems: As noted, there was a considerable amount of fare evasion associated with the use of the All-Day pass. These were issued manually by the operators, and that was not practical. Accountability for the passes was difficult. Some passengers tried to duplicate the passes. UTA gave up on selling such passes after four years.

Other Changes Planned: UTA wants to buy new fareboxes to provide more flexibility to passengers and greater accountability for fares but, due to budget constraints, purchasing new fareboxes will not occur for at least three years. The agency is also considering eliminating its current free fare zone downtown and replacing it with a free downtown shuttle. 
Agency: Visalia City Coach (Visalia, CA)

Current Fare and Transfer Policy: The base fare is $\$ 0.75$ and no transfers are issued. An All-Day Pass is available for $\$ 1.50$.

Effects of Changes in Policy: Prior to adopting the All-Day pass and eliminating transfers, the agency charged $\$ 0.75$ and issued transfers for free. Ridership and revenue increased modestly in the first two years of the change in fare policy. Ridership has declined slightly recently, but the agency attributes that to a slowed economy.

Problems: Visalia first instituted the All-Day pass prior to having farebox equipment that could issue the pass. They issued a flash pass that was punched to indicate the day issued, but they experienced significant fraud. Some passengers would try to glue the holes back into the areas of the pass that had been punched. The agency purchased new GFI fareboxes with TRIM units to correct this problem. There were only a small number of people who were riding one way trips with the need for a transfer who were disadvantaged by this change in policy.

Other Changes Planned: There are no changes planned in the near future. 
Agency: Williamsport Bureau of Transportation (Williamsport, PA)

Current Fare and Transfer Policy: The base fare is $\$ 1.50$.

Transfers are issued for free and are valid for one hour on virtually any route, but cannot be used to round-trip on the same route.

An All-Day Pass is available for only \$2.00.

In addition, a two-trip pass is available for $\$ 2.00$, although it seems unnecessary given the availability of free transfers and an All-Day pass that is also available for $\$ 2.00$.

Effects of Changes in Policy: The previous policy featured a base cash fare of $\$ 1.25$, with transfers available for $\$ 0.05$. Transfers were valid for only one-half hour and for use on certain intersecting routes. A transfer was valid for only one use.

The agency purchased new GFI Odyssey fareboxes that issued and validated All-Day passes and transfers.

Ridership has increased in the transit system, though it is difficult to isolate the effect on ridership of the fare change since there were changes in service and considerable marketing efforts as well. The agency's best estimate is that the changes in the fare policy might have increased ridership by one to two percent. The relatively high base fare of $\$ 1.50$ is driving people toward greater use of the All-Day pass.

Problems: The prior system of offering base fares and transfers was cumbersome for bus operators. They also found that the old fareboxes did not allow sufficient data collection to truly analyze the characteristics of their ridership. There were a few complaints with the change in fare structure, but not an enormous amount.

Other Changes Planned: Even though the base fare at the agency has risen considerably over the past few years (from $\$ 1.00$ to $\$ 1.50$ ), they refer to such changes as fare revisions, not fare increases, because of the many options provided to passengers. In the future, they will revise the price of the All-Day pass to provide a discount when it is purchased at an outlet versus when it is purchased on the bus. The cost when boarding a bus might be raised to $\$ 2.50$, while the price at a ticket outlet would remain at $\$ 2.00$. They hope this will speed the boarding process, if more passengers purchase their tickets at an outlet prior to boarding. 
Agency: Windham Region Transit District (Willimantic, CT)

Current Fare and Transfer Policy: This is a small agency with less than ten buses that charges a base cash fare of $\$ 0.50$. There are no transfers issued.

Effects of Changes in Policy: The agency's basic fare policy has been in effect for 15 years.

Problems: The agency reports no problems or complaints. The system is quite small, and the level of transfer activity is apparently minimal. Even though there might be cause for equity complaints among those who do have to transfer to complete a trip, the low base fare makes the price of a two-leg trip still very reasonable.

Other Changes Planned: The agency reported no plans to change its fare policy in the foreseeable future. 


\section{Summary of Survey Results}

A total of 29 transit agencies were surveyed by telephone during Spring and Summer 2004. While the previous pages outline the survey responses in detail, this section summarizes the overall results.

Of the agencies surveyed, 20 currently include transfers in their fare structure. Of these 20 agencies, 10 offer free transfers, while the remaining charge a price that ranges from $\$ 0.05$ to $\$ 0.20$, with one agency charging $\$ 0.50$. The current cash base fare of the 29 agencies ranges from $\$ 0.25$ to $\$ 1.50$. The price of All-Day passes, at those agencies that offer them, range from approximately 2.1 times the base fare to approximately 3.2 times the base fare. On average, the cost of an All-Day pass at a transit agency is 2.5 times the base fare of the agency. Of the 29 agencies surveyed, 12 currently offer an All-Day pass.

At those agencies that offer transfers, the average length of validity for a transfer is approximately two hours. In addition to a time limit, other restrictions on transfers are related to the direction of travel and the routes traveled.

Regarding transfer policy, an interesting finding is that many transit agencies are eliminating transfers altogether and moving toward all-day passes as a preferred way for passengers to pay for multiple rides on the system. Some, however, do still offer transfers with some restrictions. In total, seven of the agencies surveyed in this project have eliminated transfers (eliminated transfers or eliminated transfer fees?) within the past few years. An additional six systems that do use transfers are considering or planning to eliminate them in the near future. The remaining 13 agencies in the survey include transfers as part of their fare policies and have no plans to alter the policy in the near future.

Of those survey respondents who have eliminated transfers, the motivation was mainly related to issues with fraud and the desire to move toward new technology (e.g., smart cards, etc.). The level of fraud and passenger-operator disputes at many agencies was considered unacceptable, and the move to eliminate transfers did reduce or eliminate these problems altogether. It should also be noted that those systems that continued to issue transfers, but implemented new fareboxes that could electronically issue and validate them, also experienced a decline in fraud and disputes. New fare collection equipment also plays a role in transfer fare policy. Many agencies are looking to new technology to issue and validate various forms of fare media, including transfers, passes, and, in some areas, eventually smart cards. Several agencies are also interested in increasing the volume and accuracy of passenger data collection through new 
farebox technology. Finally, a few of the agencies surveyed (including Broward County Transit, Snohomish County, and Glendale, California) might become a part regional systems in the near future, and new farebox technology would assist in such a transition.

Some agencies wanted a change in transfer fare policy to result in increased ridership. An increase in ridership through a change in transfer fare policy could result from enhanced passenger convenience through a more streamlined, easily understood fare structure. In addition, the implementation of an All-Day pass could have a positive impact on ridership as users are induced to take additional transit trips. Most agencies that have eliminated transfers and moved to the All-Day pass did experience ridership increases, and attribute those increases, at least in part, to the change in fare policy. It is important to note that, in most cases, the agencies were undergoing other service changes at the same time as the fare policy changes.

Some agencies expected a change in fare policy to increase revenue, either from an increase in the base fare (transit ridership tends to be price inelastic; therefore an increase in the fare generally leads to an increase in revenue, all other things being equal), from the sales of multitrip passes, or through reduced fraud and fare abuse. Most agencies with these goals did experience increased revenue; a few agencies, however, believed the changes were revenue neutral, although in nearly every case there was at least one other significant service change being implemented at the same time as the fare policy.

Other motivations for changes in fare policy related to reduced costs from the elimination of paper transfers, a streamlining of the fare structure, an increase in the speed of boarding passengers (thereby reducing dwell times), and elimination of cumbersome manual processes associated with paper transfers. These and those discussed in the preceding paragraphs are the same motivations being considered by agencies who are currently contemplating a change in fare policy or structure.

As mentioned previously, the goal of many transit agencies in implementing or changing fare policy, especially with regard to transfers, is to increase ridership and revenue. An objective of this project was to gauge the effect of such policy on the ridership and revenue of transit agencies. The results of this survey demonstrate mixed results regarding the effect of transfer policy on ridership and revenue for transit agencies. Often, a new fare policy is implemented along with other significant changes for the agency such as service increases, other service modifications (sometimes including service reductions), marketing efforts, and new technology. Because of these other changes occurring at the same time as fare policy changes, it is difficult to isolate the impact of the fare policy change on ridership and revenue directly. However, one finding from this survey is that, when paired with the implementation of new fare collection 
technology, revenue was found to increase approximately five percent when transfers were eliminated.

The agencies that participated in this survey were also queried as to any problems they have experienced related to their transfer policy. Responding agencies conveyed problems that were motivations for changes in policy, as well as any problems that occurred with a new policy. Problems that were motivations for a change in policy, or contemplation of a change, were discussed previously and include fraud, passenger-operator conflicts, complicated fare structures, and time-consuming manual processes. Other problems with transfers included passenger complaints regarding the various restrictions typically placed on the use of a transfer. In general, after the elimination of transfers, very few problems or issues were reported. In a few instances, there were some relatively minor complications with the new technology (such as farebox jams) that were overcome mainly through bus operator training. One issue, however, was that a few agencies instituted passes prior to having the farebox technology to electronically issue and validate them and, as a result, they experienced problems related to the manual issuance and validation of such passes by bus operators. Overall, many of the respondents believe that the changes in policy (eliminating transfers) significantly reduced or eliminated problems.

The responding agencies were also asked if they were planning any other changes for the future. Those who made changes to their policies are generally satisfied and have no additional plans for changes in the near future. Others (seven agencies) are considering or will be purchasing new fareboxes and implementing all-day passes while eliminating transfers. New fare collection was a major issue in this survey. The latest fare collection technology involves fareboxes that eliminate the need for paper transfers and can read stored-value cards. Many agencies also like these new fareboxes for their ability to compile better ridership data, which has many uses for the agencies. Many agencies are looking forward to smart card technology to further streamline the fare collection process for the benefit of passengers, bus operators, and the agency as a whole. 


\section{Findings and Recommendations}

The purpose of this research project, conducted for FDOT by CUTR as part of the NCTR Program, was to explore how transit transfer fares and policies affect ridership and revenue, and to examine the reasoning for the implementation of these fares as it pertains to policy, budget, and operational issues for transit agencies.

This project comprised five separate tasks that were intended to achieve the objectives listed above. First, a literature review was conducted pertaining to transfer policy that summarized previous studies related to transfers. Based on results from the literature review, as well as peerto-peer discussions, a series of currently used methodologies related to transfer policy were identified in the second task of this project. From the findings of the first two tasks, a survey was developed to determine the specific components of and issues faced by transit agencies on the implementation of transfer policy and/or fare changes. Transit agencies' motivation, methodologies, and any political issues were considered. The overall intention of the survey, conducted as part of the fourth task of this project, was to collect information related to the nature of any relationship between revenue and ridership due to changes in the transfer policy and fare structure as well as any pertinent issues related to such changes. The survey findings resulted in a compilation of lessons learned from the responding transit agencies. The last task of this project utilized the results of the previous tasks to develop a synthesis of the best practices in the evaluation of transfer policy/fare changes. Successes and challenges related to these types of fare structure and policy changes are noted. Finally, recommendations are presented to assist transit agencies in gauging the appropriateness of changing transfer fares/policy and the relevance of future fare collection technology.

While this study sought to isolate the impacts of transfer fare changes on the revenue and ridership of transit agencies, very few cases were found where the transfer charge was changed and the base fare was not. In addition, most transit agencies implement new fare policy along with other significant changes, including service expansion, increased frequency, service reductions, marketing efforts, and a host of other changes that would affect ridership and revenue. As such, it is difficult to isolate the impacts of the transfer changes alone. Further, many of those transit agencies surveyed for this project specifically noted that their ridership (and revenue) had been strongly impacted by the economic slowdown of the past few years.

It was also found that transit agencies have not been changing transfer fares as much as they have been upgrading technology through new fareboxes that can issue and validate transfers, 
tickets, and other passes electronically. Newer fareboxes provide better opportunities for data collection, thereby leading to a better understanding of an agency's ridership characteristics.

The latest fareboxes have helped agencies to generate more revenue due to the significant reduction or elimination of fraud, savings on printing and accounting of paper transfers, and the ability to offer customized fare instruments to passengers to make transit (and additional rides) more attractive. In Rochester, cash revenues increased five percent after new technology was installed (GFI TRIM units) with no change in fares. Cambria County is expecting a five percent increase in cash fares when they install TRIM units. In addition, fareboxes that issue, read, and validate transfers (and other fare media) help to eliminate disputes between passengers and bus operators over the validity of a fare, and result in passengers paying the correct price for their trips.

The use of All-Day passes is exploding from just a small handful of transit agencies to a large number of agencies. The survey conducted for the project found that many transit agencies have already implemented such passes or are considering doing so. Typically, the implementation of an All-Day pass results in the elimination of transfers. This study found that prices for such passes vary from 2.1 times the base fare to 3.2 times the base fare, with an average of approximately 2.5 times the base fare for those agencies surveyed. Transit agencies that participated in this study have reported virtually no problems with changing from a fare policy with transfers to that with an All-Day pass. Passengers have been found to be very accepting, and there have been few technical problems with the new technology. Technical problems that did occur were usually easily remedied through additional training efforts.

As the literature review portion of this study found, the use of All-Day passes can eliminate many of the traditional abuses associated with transfers (such as back-riding and stopovers), they can save paper, reduce the potential for confrontations between passengers and bus operators, and they can be easier to bus operators to handle and verify. The use of such passes can also induce increased ridership because passengers can take additional trips without paying an additional fare. Also, by selling All-Day passes, an agency is selling a certain number of hours of transportation that may be used as the passenger desires; thus, this approach has been viewed as equitable because it does not penalize a particular ridership group. The results of the survey conducted for this project found these same advantages in practice.

The literature review, however, did note some disadvantages to the All-Day pass and other longer-term passes. These included the potential for different types of fare abuse such as illegal sharing, increased administrative requirements with higher-value, long-term passes, and increased paper currency in fareboxes to pay for passes. Also, these types of passes may not 
appeal to the rider who makes a single linked trip per day (typically not a large market, however). Lastly, a transit agency foregoes revenue when passengers use passes at a higher rate than pricing indicates. The survey results from this project did not find extensive problems with the use of passes. However, a few agencies that tried issuing All-Day passes manually (without appropriate farebox technology) did experience high levels of fraud and abuse. The level of abuse at Utah Transit Authority was so high that they discontinued offering the passes. Visalia City Coach in California also experienced significant fraud, but the issue was corrected when new technology (TRIM units) was implemented. This study found that, when paired with appropriate technology, the implementation of All-Day passes resulted in few problems.

Such as large number of transit passengers now ride using passes that changes to transfers (where they exist) will have much less of an effect on ridership than in earlier years before multiride fares were available. In some places, the survey found that more than half of passengers utilize multi-ride passes. It should also be noted that monthly passes based on a calendar month are not as attractive to passengers as 31-day passes that begin on the date of issue. However, many people do not care to pay for any days that they will not use the transit system and prefer to pay a reduced fare for a specific number of rides or uses.

Overall, while difficult to quantify, many transit agencies attribute increases in ridership and revenue to the elimination of transfer fares and implementation of multi-ride passes, most notably the All-Day pass. As found in the survey results, however, revenue increased approximately five percent when transfers were eliminated along with the implementation of new fare collection technology. The experiences and lessons learned of the transit agencies surveyed as part of this effort can provide information and insight to other transit agencies contemplating changes in fare policy that include changes in or elimination of transfers. The following is a list of recommendations that transit agencies should consider when contemplating such changes, based on the findings of this project.

- The percentage of passengers who transfer is a consideration. An agency with a high number of transfers might consider an All-Day pass.

- Agency size and price of the base fare are issues. Many of the smaller agencies surveyed for this project did not believe that benefits of changing the fare policy and/or upgrading technology would outweigh the costs. Similarly, those with relatively low base fares do not see a need for transfers or necessarily for All-Day passes.

- In addition to direct benefits to the agency, the convenience of passengers was also a consideration in making changes. Of course, pleased passengers will likely ride the 
system more often, and non-riders might be attracted by enhanced convenience and the ease of use associated with multi-ride passes.

- In rapidly growing areas that might evolve into regional transportation systems, individual agencies considered new technology and streamlined fare policies to prepare for integration into such a system. Many agencies were also looking forward to the use of Smart Cards.

- Agencies that wanted to significantly reduce fare abuse, conflicts between passengers and bus operators, and the often cumbersome manual processes associated with paper transfers have achieved these goals by changing their fare policies to either eliminate transfers, sell All-Day passes, or both, while implementing new farebox technology. It was found to be important to offer All-Day passes in conjunction with fareboxes that could issue and validate them electronically.

- Additional benefits of new fare collection technology include ease of use for both bus operators and passengers, ability to offer various customized fare media (although an agency should keep its fare types relatively simple to avoid confusing passengers), and enhanced data collection and compilation that can result in a better understanding of a system's ridership. 


\section{References}

1. American Public Transit Association, 2002 Transit Fare Summary.

2. Charles River Associates Incorporated, Building Transit Ridership - An Exploration of Transit's Market Share and the Public Policies That Influence It, Transit Cooperative Research Program, Report 27, 1997.

3. Curtin, John, Effects of Fares on Transit Riding, Highway Research Record, 213, 1968.

4. Dargay, Joyce, and Hanly, Mark, Bus Fare Elasticities, 1999.

5. Dygert, P., Holec, J., and Hill, D., Public Transportation Fare Policy. Sponsored by Office of the Secretary, U.S. Department of Transportation. Peat, Marwick, Mitchell and Co., Washington, DC, 1977.

6. Fairhurst, M. and Morris, P., Variations in Demand for Bus and Rail Travel up to 1974, London Transport Economic Research Report R210, 1975.

7. Fleishman, Daniel and Shaw Nicole (Multisystems, Inc.), Joshi, Ashok and Freeze, Richard (J. W. Leas \& Associates, Inc.), and Oram, Richard (Oram Associates), Fare Policies, Structures, and Technologies, Transit Cooperative Research Program, Report 10, 1996.

8. Grey Advertising, Transit Marketing Management Handbooks: Pricing, 1976.

9. Kemp, M.A. Some Evidence of Transit Demand Elasticities, Transportation, Vol. 2, 1973.

10. Lee, David, Introducing Fare Simplification and New Convenience Fares at Connecticut Transit, Transportation Research Record 1669, 1999.

11. Linsalata, Jim and Pham, Larry, Fare Elasticity and Its Application to Forecasting Transit Demand, American Public Transit Association, 1991.

12. Mayworm, Patrick, Lago, Armando, McEnroe, Jonathan, Patronage Impacts of Changes in Transit Fares and Services, UMTA - DOT, 1980.

13. Pratt, Richard, Texas Transportation Institute, Cambridge Systematics, Inc., Parsons Brinckerhoff Quade \& Douglas, Inc., SG Associates, Inc., McCollom Management Consulting, Inc., Traveler Response to Transportation System, Transit Cooperative Research Program, Project B-12, 2000.

14. Stern, Richard (Booz-Allen \& Hamilton, Inc.), Bus Transit Fare Collection Practices, Transit Cooperative Research Program, Synthesis of Transit Practice 26, 1997.

15. Stern, Richard (Booz-Allen \& Hamilton, Inc.), Passenger Transfer System Review, Transit Cooperative Research Program, Synthesis of Transit Practice 19, 1996.

16. Volinski, Joel (Center for Urban Transportation Research), Lessons Learned in Transit Efficiencies, Revenue Generation and Cost Reduction, University Research Institutes Program, US Department of Transportation, 1997. 
17. Webster, F., and Bly, P., The Demand for Public Transport, Transport and Road Research Laboratory, Crowthorne, England, 1980. 